\title{
Qualitative reappraisal of perspectives, prevalence, and management of family violence among the Yoruba people: a study of representatives of some Yoruba ethnic subgroups from lle Ife
}

\author{
Omolola Irinoyea, Oluwasayo Bolarinwa Ogunlade ${ }^{\mathrm{b}, *}$ \\ aDepartment of Nursing Science, College of Health Sciences, Obafemi Awolowo University, Ile Ife 220, Nigeria \\ 'Medical and Health Services, Obafemi Awolowo University, Ile Ife 220, Nigeria
}

Received: 4 February 2020; Accepted: 26 April 2020; Published: 20 December 2020

Abstract: 0bjective: The analysis of changing definitions and perspectives of violating behaviors within cultural contexts will inform the responses and interventions that will mostly reduce the occurrences of family violence.

Methods: This study used focus group discussions of purposively selected participants to generate data that were analyzed using content with themes of definition, perspectives, prevalent forms, persons mostly affected, perpetrators, and management strategies among the Yoruba people.

Results: There were multiple words and descriptions in the local Yoruba language for abuse and violence, but no single word for either of the two concepts. Common forms of family violence identified were verbal assaults from parents to children, among couples, siblings, physical assault of children by parents, physical assault of parents by children, neglect of children, parents, spouses mostly wives, sexual harassment, and sexual violence. Neglect of wives and children was perceived to be increasing, occurring in one in four houses. Sexual harassment and sexual violence were perceived to be rare, but the latter not an issue in marriage. A variant of sexual "touching" said to be tolerated with unmarried young people was identified as common among this ethnic group. Age and gender were dominant factors in the use of common forms of violence. Informal approaches were methods of management of family violence but perceived inadequate.

Conclusions: This study concluded that family violence is a common phenomenon occurring among family members. Hence, formal acceptable interventions that will be appropriate for this ethnic subgroup are required.

Keywords: family violence $\bullet$ qualitative reappraisal $\bullet$ definition $\bullet$ management $\bullet$ Yoruba people

(c) Shanxi Medical Periodical Press.

How to cite this article: Irinove O, Ogunlade OB. Qualitative reappraisal of perspectives, prevalence, and management of family violence among the Yoruba people: a study of representatives of some Yoruba ethnic subgroups from lle Ife. Front Nurs. 2020;4:385-398. 


\section{Introduction}

Family violence is a construct in family relationship which has continued to be the focus of research, policy formulation, policy review, and conceptualization of services over time. Interventions need to adopta construct for an integrative approach aimed at the prevention and management of violence. ${ }^{1,2}$ The relevance of an all-inclusive construct to prevent fragmentation and promote an integrative and comprehensive approach to intervention is being captured by many countries. ${ }^{3}$ However, the meaning of the construct family violence differs across cultural contexts.

There are different cultural perceptions about violent behaviors. Some behaviors recognized as forms of violence are termed as normal behaviors in particular populations with dearth of literature on the various definitions from different cultural perspectives. ${ }^{4}$ The Government of Western Australia defined and clarified the terms family violence and domestic violence; domestic violence as abuse against an intimate partner, while family violence, a broader expression encompassing family, domestic violence and the abuse of children and other family members. ${ }^{3}$ In Nigeria, the Violence Against Person Prohibition (VAPP) Act of 2015 presents violence as any act or attempted act that cause or may cause harm to a person physically, sexually, psychologically, verbally, emotionally, or economically in either private or public life and in peace or conflict situations. ${ }^{5}$ The Nigerian definition appears all-encompassing as it captures every form of violence that can be imagined within the home and in the society with an ambiguous impression without specifics of forms occurring in relation to family relationships. Nigeria is a country with about 250 ethnic groups with their varying languages and associated beliefs assigning different meanings to the construct under question depending on the particular ethnic group. Worthy of mention is the subculture theory of violence as the cultural explanations for permissive violent behaviors under certain conditions as inherent in the values and norms of a particular culture. ${ }^{6}$ This theory also argued that violence may be seen a product of conformity to a violent subculture; with violent reactions as normal occurrences for the protection or maintenance of reputation. ${ }^{6}$ Some of the subculture theory of violence may be present among the Yoruba ethnic subgroup in Nigeria. However, there is dearth of literature about the meaning of the construct of family violence as perceived by the Yoruba ethnic group of Nigeria. Hence, the exploration of the construct family violence among the Yoruba ethnic group, 1 of the 250 major ethnic groups in Nigeria, for the development of interventions will be acceptable in relation to their perspectives of the problem.
Importantly, behaviors that would be conceptualized as violence in relationships within different ethnicities and their cultural contexts may vary. ${ }^{7}$ These may be related to normative disciplinary behaviors such as they are related with various ethnic groups in Nigeria. Violating behaviors among family members in Nigeria has continued to be researched as fragments often in the context of gender-based violence, ${ }^{7,8}$ intimate partner violence,,$^{8,9}$ child abuse ${ }^{10-12}$ and elder abuse. ${ }^{13}$ While these empirical data are available about some forms of abuse and violence, and about victims and perpetrators as they affect some individuals in the family perhaps as vulnerable groups, it is of importance to analyze and understand all forms of violence within the social undercurrents of family relationships with its implicative meaning among the various ethnic groups to inform specific family-centered interventions. ${ }^{7}$ The interventions will have to consider the order and system of authority that permeate the particular ethnic group with the motive for an in-depth understanding of such social dynamics in the particular cultural context for relevance and acceptability of such interventions as they may be among the Yoruba ethnic group.

This study was conducted to give more understanding to the construct of family violence as it occurs in the context of the family as the basis for perception, learning, understanding, occurrence and management of family violence among the Yoruba people. This is with the basis that the family is the primary socialization structure where children's behaviors are modeled to responsible adults with the appropriate healthy relationship skills. The Nigerian Demographic and Health Survey $2018^{14}$ showed a prevalence of spousal violence to be $36 \%$ higher than $2008(31 \%)^{15}$ and 2013 $(25 \%) .{ }^{16}$ The review of documented management strategies through standard interventions for perpetrators, victims, and survivors had inconclusive reports for effectiveness, ${ }^{17}$ thereby allowing for more innovative management strategies that may have long-term effect on preventing family violence reoccurrence, hence the reason to assess what some of the sub-ethnic Yoruba groups perceive to be family violence to generate information for intervention development. In addition to giving information about a group of people or community orientation about family violence, the qualitative study was done to also help moderate or modify other instruments that are to be used for other quantitative measures in a future population-based study to guide formulation of hypotheses and to give some cues to what is needed to be built into intervention. This was to provide information to guide family-centered intervention programs for a culture-specific group with partnership at the community level. 


\section{Methods}

\subsection{Study design}

This study adopted the exploratory-descriptive qualitative design to explore the definition, prevalence, and management strategies of family violence among the Yoruba ethnic group in a town in south-western Nigeria. This design was utilized because of the need to define the construct of family violence from the context of the main Yoruba ethnic group and some of her subgroups resident in Nigeria. Focus group discussion (FGD) was used to generate information from six categories of people across three generations that constitute the family among the Yoruba ethnic group in Ile Ife. These were females and males within the age groups of 18-24 years, 25-45 years, and above 50 years. Inclusion criteria were been a Yoruba by birth, must have grown up within the Yoruba culture, and lived all their lives in a Yoruba town and among Yoruba people. The exclusion criteria were Yorubas by birth but were not raised within the Yoruba culture and customs, and travelers not residents of Ile Ife.

\subsection{Study setting}

The study location was lle Ife, an ancient town in Osun state, south-western region in Nigeria. Ile Ife is the origin of the Yoruba ethnic group that migrated across the world. The Yoruba ethnic group also has various ethnic subgroups with differing dialects and cultural beliefs, but there are areas of congruence in cultural beliefs and a common Yoruba language synchronizing all from the Yoruba ethnic descent. Ile Ife is a town with the indigenous people who engage in agriculture along with other circular jobs. ${ }^{18}$ Ile Ife also accommodates a prestigious tertiary institution: the Obafemi Awolowo University with a philosophical principle of learning and culture.

\subsection{Study participants}

Informal consultation was made with colleagues, friends, coworkers, and some acquaintances in Obafemi Awolowo University lle Ife. Participants were drawn among the individuals within the university community, resident in the town of lle Ife, adjudged by peers, colleagues at work to be adept in Yoruba culture and grew up within traditional Yoruba family settings. Names suggested were approached having ascertained to meet the inclusion criteria for participation. Appointments for the discussions were scheduled by groups according to age. The male youth group had 8 participants; female youths group had 9; female middle-aged adult group had 9; male middleaged adult group had 10; male older adult group had 10; and female older adult group had 9.

Data were generated around six themes:

1. Definition of abuse and violence within the family context among the Yoruba people.

2. The general perception of violence in the family context among the Yoruba people.

3. Prevalent forms of violence and the extent of occurrence.

4. Prevalence and consequences of violence in the family.

5. People affected mostly by violence, perpetrators of violence, and its common causes in the family context.

6. Approaches usually adopted for prevention, management, and control of violence within family relationships.

\subsection{Data collection}

The Institute of Public Health Ethical Review Board in Obafemi Awolowo University Ile Ife (IPH/OAU12/1190) approved the conduct of this study. Written informed consent was obtained from all participants.

Three persons were involved: the principal investigator moderated the session; the co-investigator took notes; and a support person ensured the comfort of informants. The FGDs were conducted in a roundtable sitting arrangement with a small voice recorder that taped the FGDs with the consent of participants. Each session started with self-introduction of all participants, followed by a general introduction of the construct under study with emphasis on the interest in Yoruba ways of life, familial relationships, and modes of regulating family relationships to the prevention, management, and control of abuse and violence. Following an expression of understanding of the motives and information about how the session would go, the moderator then posed the questions and probe as necessary. Each session was concluded by expression of appreciation to participants and light refreshments. The sessions lasted from 80 to $95 \mathrm{~min}$. The sessions with the youth took longer periods as some education has to be done along to get them to understand some of the constructs and get the best out of the young people. The sessions were audio-recorded with the permission of the participants.

Data analysis began with the verbatim transcription of the audio-recorded interviews which was later translated into English language. Thematic analysis approach was used to examine the data further after reading the transcripts and listening to the recorded interviews. 


\section{Results}

The participants' variables showed that some had lived in rural and urban Yoruba settings, and some had lived in urban settings only-but all had lived in lle Ife town for 5 years or more. All participants in each group have comparable education and socioeconomic status. All middle-aged female adults had secondary school education and were either arranged into trading, vocational job, or the combined job of the two. All middleaged male adults also had secondary school education. Three of these were clerical staff in the university, three were artisans/technicians, and three were typists. All older male adults had secondary and postsecondary education though none had a university education, and the highest had the ordinary national diploma. Two were teachers in a primary school, two were technicians, three were administrators, and three were in private businesses. All older female adults had secondary and some postsecondary education. One was a nurse, two were secretaries, two were teachers, and three were in private businesses.

\subsection{Definition of abuse and violence in the family context among the Yoruba people}

A primary challenge was encountered in the attempt to translate the key words of abuse and violence to Yoruba language. There is no single Yoruba word that has the equivalent meaning of abuse or violence. Attempts to have Yoruba words that would best express the construct "abuse and violence" generated the following words as given by the participants.

Abuse is "Ireje" (cheating), "Iwa koto" (behavior that is not appropriate), "ilokulo" (misuse), "Ilo aibikita" (carefree use of another person), "Ilo Iwosi" (insulting use), "Iwa aidaa" (bad behavior), "Ilo akisa" (use of a person like rag), and "llo egbin" (using someone in a foul way).

Violence is "Iwa ipa" (behavior characterized by the force) or "Iwa kan an npa" (behavior of forcing others), "asemase" (misconduct), "Iwa tipa ti kuku" (behavior characterized by kicking and boxing), "Igbaju-igbamu" (different forms of slapping), "Se lese" (wound), and "Se ika fun" (be brutal to). The appreciation of the absence of a single Yoruba word that gives the same meaning to the English word abuse but described by the group before as closed after abused with a period. Violence was agreed upon by the groups after sufficient probing as "An act of a person(s) characterized by the use of force, intended to cause physical (injury) and emotional harm or material deprivation that hurts another person(s)."

\subsection{The general perception of violence in the family context among the Yoruba people}

The young adults (18-24 years) could not concisely describe the constructs but gave examples of what they know the Yoruba people would consider as abuse. Behaviors readily given by both male and female young adults were situations of men having extramarital relationships. According to a 20 -year-old male, "a married man having extra marital affairs to the extent of having children with the mistress with his wife innocent would be considered to have abused his wife." Another example given by a 19-year-old (male) was "a father having sex with his daughter is committing an act of abuse."

The middle-aged male adults stated that extramarital affairs by the man especially to the knowledge of the wife was also said to be abusive. A 36-year-old male artisan said "An abusive behaviour that the husband can manifest to the wife is to bring another woman or a concubine home."

To the middle-aged women, abusive behavior includes failure of the husband to meet up with the social role of making provisions for the family. A 38-year-old female trader stated that "God put the responsibility of upkeep of the home on the head of the husband. Many have left this undone, they also eat out of the woman's sweat."

The older male adults viewed abuse and violence in the family from the perspective of failure to meet up with societal assigned gender roles or poor performance of such roles as the husband, wife, or parents. A 34-yearold male teacher said, "while talking about what Yoruba people would consider an abusive relationship in the family, there is need to understand their position about role assignment, and obligation to perform such assigned duties in the family. Whoever fails to perform assigned roles and duties will be considered to be abusing the other members of the family. Although there were sanctions in the past for not performing assigned roles."

A single Yoruba word was not available to give the exact meaning of violence. According to the participants in the FGD, violence among the Yoruba language was described in behavioral terms of "Iwa gbodonroso" (behavior depicting chronic disagreement), "iwa tipatikuku" (behavior characterized by kicking and boxing), "iwa jagidijagan" (doing everything with force), "iwa kanpa" (insisting on force with others), and "iwa alase-onikumo" (behavior of authority that defiles). Violence is condemned among the Yoruba people from the findings from all the groups, but whether many behaviors termed as abusive and violent in modern 
times would be qualified to be so in the traditional setting was raised by the adult women. For example, ladies married into the family as wives are symbolically seen as slaves in the larger family context. This position is a risk factor that exposes women to abuse in the extended family system. According to a 38-year-old female trader, "our forefathers take wives to be slaves in their husbands family context, where work to be done jointly by the couple is solely carried out by the wife. For example, if the husband and the wife are going to the farm, the husband would only hold his hoe, the wife may be pregnant, carry a child on her back, and also carry all the loads the couple are taking to the farm. Wives are equally expected to treat younger family members as senior persons to be respected and not called by their first names."

The construct abuse and violence were differentiated by all the groups but emphasized that both are harmful to the person exposed to either. Female youths expressed that while violence is done intentionally many people abuse others without knowing. Male young adults specifically pointed out the abuse of younger wives by older wives and that older wives tend to put the performance of house chores on the junior wives within the household during festivities putting a lot of stress and pressure on such younger wives. The group also identified the custom of the Yoruba people insisting a newly married young wife is not allowed to call children who are her in-laws by their names without some forms of reference as abusive. Widowhood rituals, making widows wear a black item as part of her dressing and movement restrictions for a year after the death of her husband but not applicable to widowers were also identified as abusive and gender discriminating by young adult men. Fathers having sex with their daughters or older siblings having sex with younger ones are particularly considered as violence by female young adults.

\subsection{Prevalent forms of violence and the extent of occurrence}

The identified forms of violence as indicated by the groups are presented in Table 1. Many of the views were expressed along with some explanations as indicated. The perpetuation of identified forms of violence in the family according to the various groups were classified as controlled $(\mathrm{C})$, tolerated but controlled (TBC), and tolerated but approved as bad (TBB) with punishments given to reduce reoccurrence. Some were not tolerated (NT) at all and tend to receive severe penalties. Some were considered as "eewo" abominations (A) with associated culturally believed consequences in the traditional society while some were not recognized
(NR) as an abuse or violation. The groups emphasized that no person is given the freedom to assault either verbally or physically. According to a 59-year-old civil servant "even the use of verbal abuse to correct erring children is supposed to be controlled among the Yoruba people. There are languages one cannot use. When such languages are used for children by parents or older persons, they are also liable to be reprimanded by older people if they get to know. There are rules about everything, how to correct, what to use, and alternatives that should be considered."

These views were also corroborated by a 36-year-old woman trader who said the word that besides meeting a young child in the act of doing a bad thing and simply spanking the child on the buttocks with the palm or slim cane, the Yoruba people usually appreciate reporting someone who does a bad thing. Several reports of a particular bad person are supported to be beaten by the older people. If one offend someone and that person run to the elders, Yoruba people believe that such an offender already acknowledges his/her misbehavior and would be mandated to seek for forgiveness but should never repeat such a thing again.

A 45-year-old male ljesha teacher also emphasized that Yoruba people are also skeptical about unregulated use of beating as a corrective measure. According to him, Yoruba people across the board believe that "omo tabi iyawo ti a ba n lu ni gbogbo igba yi o ya pokii tabi ki o yi igbe, ko si ni gboran mo" (a child or wife who is beaten all the time would get accustomed to being beaten and would not take to corrections again). The context of regulated beating in itself is a challenge for the control of family violence.

A particular phenomenon raised by a 55 -year-old nurse and corroborated by the information from all groups is the Yoruba view of a child who has outgrown spanking or beating and will only receive a sign of disapproval when he/she misbehaves. Enquiry of some languages that can be termed abuse in modern times revealed that the use of languages like "yio ba baba e" (your father be spanked) and "yio ba furo ya e" (your mother's butt be spanked) among the Oyo Yoruba people is banter between older wives in family compounds and the children of the family compound or older men with wives of the family compound was raised. According to a 59-year-old Ogbomosho man, it was not unusual to hear this phrase, as used by older wives to tease young people from the family compounds of their husbands or as used by older men from the family of the husband using such languages in lighter moods.

A 45-year-old ljesha teacher, however, commented that such comments are not acceptable and not used among the ljesha people reflecting some variations by the sub-ethnic group. However, among the ljeshas, the 


\begin{tabular}{|c|c|c|c|c|c|c|}
\hline Forms of abuse and violence & $\begin{array}{l}\text { Female } \\
\text { old adults }\end{array}$ & $\begin{array}{c}\text { Male } \\
\text { old adults }\end{array}$ & $\begin{array}{c}\text { Female } \\
\text { middle-aged adults }\end{array}$ & $\begin{array}{c}\text { Male } \\
\text { middle-aged adults }\end{array}$ & $\begin{array}{c}\text { Female } \\
\text { young adults }\end{array}$ & $\begin{array}{c}\text { Male } \\
\text { young adults }\end{array}$ \\
\hline Verbal assault from children to parents & NT & NT & NT & NT & NT & NT \\
\hline Verbal assault from parents to children & TBC & TBC & TBC & TBC & TBC & TBC \\
\hline Verbal assault from husband to wife & TBB & TBB & TBB & TBB & TBB & TBB \\
\hline Wife to husband & NT & NT & NT & NT & NT & NT \\
\hline \multicolumn{7}{|l|}{ Sibling to sibling } \\
\hline - Older sibling to younger sibling & TBC & TBC & TBC & TBC & TBC & TBC \\
\hline - Younger sibling to older sibling & NT & NT & NT & NT & NT & NT \\
\hline $\begin{array}{l}\text { Physical abuse/assault in family interaction, } \\
\text { e.g., beating of parents by children }\end{array}$ & A & A & $A$ & A & A & A \\
\hline $\begin{array}{l}\text { Physical assault of children, e.g., beating of } \\
\text { children by parents }\end{array}$ & C & C & C & C & C & C \\
\hline Wife assault by husband & TBB & TBC & TBC & TBC & TBC & TBC \\
\hline Husband assault by wife & NT & NT & NT & NT & NT & NT \\
\hline Older sibling's assault of young sibling & TBC & TBC & TBC & TBC & TBC & TBC \\
\hline Younger sibling's assault of older sibling & NT & NT & NT & NT & NT & NT \\
\hline Assault of the elderly person in the family & A & A & A & A & A & A \\
\hline Sexual assault of children & A & A & A & A & A & A \\
\hline Sexual assault of wife by husband & NR & NR & NR & NR & NR & NR \\
\hline Sexual assault of husband & A & NR & NR & NR & NR & NR \\
\hline Sexual assault of sibling & A & A & A & A & A & A \\
\hline Sexual assault of older people & A & A & A & A & A & A \\
\hline Neglect and abandonment of children & NT & NT & NT & NT & NT & NT \\
\hline Neglect and abandonment of wives & NR & NR & NT & NT & NT & NT \\
\hline Neglect and abandonment of husbands & NT & NT & NT & NT & NT & NT \\
\hline Neglect and abandonment of elderly people & NT & NT & NT & NT & NT & NT \\
\hline
\end{tabular}

Note: NT, not tolerated; TBC, tolerated but controlled; TBB, tolerated but approved as bad; A, abominations; C, controlled; NR, not recognized.

Table 1. Identified forms of violence and the perceived societal responses.

use of the language especially as a prefix to request and general interaction such as "Ki o ba ni roran ..." (if you are not going to get into serious problem ...) is also said to be common in general interaction among the ljesha people which are also not acceptable among the Oyo Yoruba or other sub-ethnic groups.

\subsection{Prevalence and consequences of violence in the family}

The summary of the groups' views about the prevalence of identified forms of family violence is presented in Table 2. Levinson (1989) had earlier used the grading adopted in determining the prevalence of family violence in his study. The grading used to estimate the degree of prevalence of various forms of family violence is at four levels of (-) rarely occurs or absent; (+) occurring in almost one of four households; $(++)$ occurring in every other house; and $(+++)$ occurring in almost all or nearly all households. But other two levels were added as: $\left({ }^{*}\right)$ identified form of abuse/violence rarely occurs or absent but appeared to be on the increase relatively to what used to be in the past but would not fall into any of the other categories. $\left(-^{* *}\right)$ groups were very emphatic about the increasing prevalence. Verbal assault of children is a dominant form of abuse but seen in the language of correction of children in the household as supported by all the groups. This was explained from the perspectives of training a child to be responsible and to correct children when they misbehave. Verbal assault is also common among siblings, especially from older to younger siblings. These observations recognize the age-related requirement of the older individuals' responsibility for the appropriate socialization of younger persons among the Yoruba people. It is the first-level disciplinary approach. According to a 49-year-old female trader, most of the times when children are corrected, we verbally abuse the child. A child who takes to verbal reprimand would not be exposed to a physical beating by strokes of the cane. There are various forms of verbal reprimand though. There are times when all that needs to be said to the child is "your head is bad" or "take your mouth 


\begin{tabular}{|c|c|c|c|c|c|c|}
\hline \multirow[t]{2}{*}{ Forms of abuse and violence } & \multicolumn{6}{|c|}{ Perceived level of prevalence as indicated by groups } \\
\hline & $\begin{array}{l}\text { Female } \\
\text { old adults }\end{array}$ & $\begin{array}{c}\text { Male } \\
\text { old adults }\end{array}$ & $\begin{array}{c}\text { Female } \\
\text { middle-aged adults }\end{array}$ & $\begin{array}{c}\text { Male } \\
\text { middle-aged adults }\end{array}$ & $\begin{array}{c}\text { Female } \\
\text { young adults }\end{array}$ & $\begin{array}{c}\text { Male } \\
\text { young adults }\end{array}$ \\
\hline Verbal assault from children to parents & - & - & - & - & - & - \\
\hline Verbal assault from parents to children & ++ & ++ & ++ & ++ & +++ & +++ \\
\hline Verbal assault from husband to wife & + & + & ++ & ++ & ++ & ++ \\
\hline Verbal assault from wife to husband & + & + & + & + & + & + \\
\hline \multicolumn{7}{|l|}{ Sibling to sibling } \\
\hline Older sibling to younger sibling & +++ & +++ & +++ & +++ & +++ & +++ \\
\hline Younger sibling to older sibling & ++ & ++ & ++ & ++ & ++ & ++ \\
\hline $\begin{array}{l}\text { Physical assault, e.g., beating of parents } \\
\text { by children }\end{array}$ & - & - & - & - & - & - \\
\hline $\begin{array}{l}\text { Physical assault of children, e.g., beating } \\
\text { by parents }\end{array}$ & +++ & +++ & +++ & +++ & +++ & +++ \\
\hline Wife assault by husband & + & + & ++ & ++ & ++ & ++ \\
\hline Husband assault by wife & - & - & - & - & - & - \\
\hline Older sibling assault of younger sibling & + & + & ++ & ++ & ++ & ++ \\
\hline Younger sibling assault of older sibling & - & - & - & - & - & - \\
\hline Assault of the elderly person in the family & - & - & - & - & - & - \\
\hline Sexual assault of children & - & - & - & - & - & - \\
\hline Sexual assault of wife by husband & - & - & - & - & - & - \\
\hline Sexual assault of husband & - & - & - & - & - & - \\
\hline Sexual assault of sibling & - & - & - & - & - & - \\
\hline Sexual assault of older people & - & - & - & - & - & - \\
\hline Neglect and abandonment of children & + & + & + & + & + & + \\
\hline Neglect and abandonment of wives & + & + & $+^{*}$ & + & $+{ }^{\star}$ & $+{ }^{\star}$ \\
\hline Neglect and abandonment of husbands & - & + & - & $-{ }^{\star}$ & - & - \\
\hline $\begin{array}{l}\text { Neglect and abandonment of elderly } \\
\text { people }\end{array}$ & $-\star \star *$ & $-\star \star$ & $-\star \star$ & $-\star \star$ & $-\star \star$ & $-* \star$ \\
\hline
\end{tabular}

Note: The identified forms of violence classified with these $\left(-{ }^{*},-^{* \star}\right)$ signs from all the groups are associated with serious economic hardship that has gradually become part of life among a high number of young families who ordinarily take responsibility to care for their elderly members in the extended family.

Table 2. Views about how common identified forms of violence among the Yoruba people by groups.

away" for the child to know that the act performed is unacceptable.

Another 45-year-old ljesha man also emphasized that Yoruba people uses verbal reprimand in form of commending and advising to tell the person that "oro lomo eleti nje" (one's ears are meant to be used to listen to words of warning) and that when a person fails to listen to caution and words of reprimand that use of alternatives become useful. The man emphasized that this is common as the child leaves "infancy" to maturity with a reasonable level of understanding of the issues at stake. Specific controls of the use of violence such as beating of children within reasonable limit, not beating a child at random nor in annoyance, and without causing injury to the child are specified controls acceptable to the Yoruba people to correct an erring child. The women groups particularly emphasized that if a child is spared, the child will "be spoilt" and that "nina ko kin pa omo" (beating does not kill the child) and that "omo ti o ba dara ni ti baba, eyi ti o ba baje tiya e ni" (the good child will be claimed by the father, the bad one is abandoned to the mother) justifying why women must discipline the children. A 35-year-old civil servant female claimed that "ko si omo ti ko ki nfe baje, iya re ni ko ni gba pelu ibawi enu ati egba teere" (there is no child that does not go in the way of becoming spoilt, it is the mother who would not accept such from the child with verbal reprimand and beating with a tiny/slim stroke of the cane). Almost everyone believes that it is not rational to be emphasizing neglect and abandon of such children by the husband.

However, every group also noted that marrying more than one wife have its own problems. By consensus, in the groups, family violence is said to be common among illiterate people in the low socioeconomic status, more among the ljesha and 
Ekiti, and less among the Oyo-Oyo, Ogbomosho, and Saki people. Family violence tends to occur more in inter-ethnic marriages, such as ljesha husband/ljesha wife combination and less in Oyo husband/Oyo wife combination. However, the older male group indicated that there is less violence in marriages across subethnic groups as Yoruba people tend to be more tolerant of people coming into their family from other ethnic and sub-ethnic groups different from theirs. Significantly, a form of sexist touching which in modern times would be taken as sexual harassment was shown as common and tolerable among the Oyo Yoruba people but not acceptable among the ljesha sub-ethnic group especially among unmarried young people. According to the older male adults, it is not unusual among young unmarried men and women to witness a young man mischievously touching the breast or gently tapping or slapping the buttocks of a young woman in a sexist gesture or advances in what the Yoruba referred to as "tage." According to a 56-year-old man from Ogbomoso among the Yoruba people especially among artisans and drivers, young men usually touch young unmarried women by gently slapping the buttocks or touching the breast without any seriousness. The woman would usually protest that she does not like it. This sexist touching with married women is loathed among the Yoruba people.

This phenomenon was only raised by older male adults. The younger male adults specifically noted that it is bad to touch a woman who is not one's wife. However, male older adults emphasized that rape was not an issue among the Yoruba people in the past as occur in recent time because childcare specifications and living pattern were used to regulate sexual interaction. More so, there was limited sex for pleasure but more for procreation. Polygyny was also identified as something used by men to have access to more women for sexual intercourse. Widowhood could allow for free sex but was said to be regulated for women because women whose husband died would be prompted to be remarried to another person in the family of the dead spouse in the past but not acceptable in recent time.

Identified consequences of violence in the family by all the groups include attempts at suicide, physical injuries of the victim, frustration of the person perpetuating violence, fear, and confusion of children in the family. Others were couples' and in-law's unhappiness, seeking for external comfort away from the relationship or home, absence of peace in the home, and divorce. Young female adults particularly identified the negative effect of violence on the children to be unhappiness and failure to meet the needs of children.

\subsection{Victims and perpetrators of family violence in the family context}

The people mostly affected, as identified by young adults (females and males), are children and women. Young adult males emphasized that women often endure such abusive behaviors for the welfare of their children. This is done to avoid being deprived of the access to their children because they would not want to leave the children in the care of another woman if they attempt leaving the relationship. A 22-year-old male said "Women are more exposed to all the suffering, children don't experience the abusive behaviors all the time but women do for the happiness of their children to shield them from violent behaviors."

This was supported by a 56-year-old female teacher who expressed that Yoruba women usually bear suffering for their children for a better future for the children. Men cannot do the same for their children. It is the mother who takes the burden of such things so that the child would not get accustomed to abuse especially from a father deemed to be harsh. But there are some women who can kill a child with beating if they are allowed.

Old adult males and females also highlighted women as the most affected and all the groups were unanimous about men (father) as perpetrator though female young adults emphasized that older siblings also perpetuate violence within the family.

\subsection{Perceived causes of violence in family relationships}

The usual causes of abuse and violence in the family are the failure to perform expected roles, fulfill obligations, and lack of love. A 36-year-old artisan commented that if the husband goes to work, left allowance for food before going, and the wife does not care to prepare food until the husband comes back, if the husband beats such a wife, Yoruba people do not see anything bad in this behavior.

Men also abuse and violate their wives on suspicion of infidelity. Male young adults specifically identified barrenness of the woman, uncaring attitude of the woman, higher income of wives than that of husbands, laziness of the woman, and the woman engaging in gossips as risks to have been exposed to abuse and violence by their husbands. Female young adults indicated drunkenness as a cause of abuse and violence by men but also commented that "nkan ti o ba wa ninu eeyan ni oti maa npa ni mo" (it is what is in the subconscious that gets manifested when drunk). Men's greed and tolerance of their bad behaviors by the society are factors enhancing abuse and violence by men. 


\subsection{Management approaches of family violence}

The approaches for prevention and control of family violence among the Yoruba people by the older male adults indicated that people were raised with family values that some behaviors were not acceptable. They also explained that young people are afraid of elderly family members so as to avoid whatever is not acceptable in the larger family fold. It becomes an abomination for the children in the family to engage in such "unacceptable acts" since reprimands, showing disapproval is used as preventive measures against reoccurrence. An example of a man beating his wife without the recourse of reporting the wife to older people even when that wife does something wrong, elders in the family compound could ask the "Omo-ile" (the male children in the family compound) to beat the man as a corrective measure. Where the man fails to change, his mother will be involved to call her son to order. According to them, the mother of the abusive husband would be called by the elders to take her child who does not conform with the norms of the family to where she brought the child as the child who is not a bastard would behave in consonance with the family standard.

While this observation reflects disapproval of intimate partner violence, it has also brought to the fore the context of "woman blaming" for an adult's misconduct a common occurrence when a child misbehaves in a family relationship. This becomes a challenge preventing intimidation and psychological abuse of women with the implication for gender-based violence. Young men also stated that stories, usually in the form of "alo" (folktales), were also used to educate young children in the family compound and sermons in religious houses were other approaches identified to be in use in recent times. All respondents added that the older people among the Yoruba people in the past regularly give counsel through the sharing of experiences and general discussions to discourage unwholesome behavior in the family through several media of communication not currently explored. Female youths were emphatic on Yoruba people insistence that any offended person in the family context should report to older persons-children report perpetrators to parents or older family members, husband reports wife to older in-laws, and wife reports husband to older in-laws and family members without taking "law into their hands." They stressed that children can report parents to grandparents or older members of the family or parents' friends.

Active management of violence in the family is through the intervention of older people (or significant persons such as close friends to the family) who would usually convene a meeting inviting elderly people who are in control and can give instructions to people involved and would be expected to obey. Children as they grow up can also act as control measures for reducing the occurrence of violence with their parents, insisting that their parents especially fathers should stop perpetuating acts of abuse or violence against their mothers or siblings. Older family members from the family of the couple could call a meeting and formally put a stop to the occurrence of family violence. According to female adults (old and young), elders in the neighborhood and the family are always the one who does this where couples are known to perpetuate violence. With the consensus that it is the victim, whomever it is in the family that usually report, there can also be variance where a parent reports a child or a child reports on behalf of the mother who is a victim. The group also indicated that resolution always follows a process of reporting an offense by a member of the family to older responsible persons initially. The steps of the resolution include asking people involved to state their sides of the incidence, followed by elders asking questions and seeking clarifications. "Resolution" as reported always comes in the ways of apportioning blames and giving instructions to all parties to prevent reoccurrence.

It was emphasized however that there would not be incidence requiring such intervention that all parties involved would not be apportioned some blames, especially emphasizing people failing in their responsibilities or taking laws into their hands. Intervention by family members is very crucial to the prevention of reoccurrence and with specifications of whom to report in the future as stated by older male adults. Different religious bodies are also said to have ways of controlling family violence. Although, there was a consensus that Islam is tolerant of violence even in the family. According to a 45-year-old technologist, "Islam is in support of husband beating his wife."

The forms of violence easier to manage from male youths and older adults perspectives were verbal and physical assault. The people who are involved in prevention and management of family violence among the Yoruba people currently as identified by the groups include parents of couples, older people (elders) in the nuclear and extended family, the head of the youths in the family compound, the heads of the family ("bale"), friends of parents, elders in the community, and religious leaders. The fathers-in-law according to female young adults are usually more supportive of the wives of their sons, but mothers-in-law usually take sides with their sons in attempt to resolve or manage violence in the family, especially where the wives are victims. This observation raises the extent to which older women stand in the gap to prevent violation of the younger women. 
All the groups indicated that all categories of health care workers, social workers, law enforcement agents, the judiciary, and other traditional and social groups do not play significant roles in the prevention and control of family violence. The young female adults indicated that if anything, "the police make matters worse because they are not women friendly." Male older adults emphasized that the police are more of threat than help in managing family violence because they perpetuate violence in their relationships. Customary court are seen to adjudicate and are better in intervention to manage family violence as they always adopt Yoruba method of crisis management of a "win-win" resolution of crises with the mandate that elders in the family of people affected should also take responsibility for helping to finally resolve the cause of violence. This is unlike the magistrate and high courts that more often than not use the "win-lose" approach that is considered unwise in the Yoruba participants' analysis. The "win-win" approach seems acceptable to the participants from this ethnic subgroup because it gives the opportunity for reflection and self-restraints on the individuals involved in prevention and reoccurrence. Further exploration of management approaches considering different forms of violence revealed a consensus of similar approaches of management. The severity of injury according to the participants always results in strong disapproval of the violent act prompting family members' approval of separation of the victim(s) from the perpetrator(s). According to a 45-year-old ljesha teacher, the parents of the husband who has beaten his wife or children so badly at times, especially when they can afford it, could take the wife or child away from the man and expect him to come back and take his wife or child when he is sober with a pledge of not repeating the act again.

Father-in-laws play counseling, adjudicating, and supportive roles. Fathers sanction their sons and daughters. "lya ile" (oldest wife) in the traditional family compound also gives directives, guide, and counsel young women on managing interpersonal relationships and approaches to resolving conflicts in the past. On the perceived degree of effectiveness of these approaches on prevention and control, the consensus was that all these approaches used to be effective but are no longer effective in modern times. According to the older male adults, "the family cordiality that used to be strong such as to help build and assure control is no more." The extended family and parents who use to be able to instill discipline and control have lost such control and this has resulted in a high prevalence of abuse and violence. They commented that people have become so individualistic and that this does not make room for sufficient group control. According to a 45-year-old ljesha teacher:

"We no longer have people behaving like having blood relations, but behave like strangers staying together. The togetherness is not like in the past at home and workplaces. Living together, bestows commitment to family members in the olden days. There is no respect for older people, and when respect is not given as dictated by age, the world cannot be organized. For change to occur, we must return to our old practice of seeing ourselves and relating together amicably. This is what would not allow people to just do things anyhow in their own family".

Women generally hold the view that better ways of making men more responsible and control their violent act must evolve. They are of the view that there are a lot of contradictions in the modern systems that give room for men doing what they like. Women are ambivalent about using the modern approaches of law enforcement agents and the law court. One 38-year-old female trader said, "Relationships, where children abound among the Yoruba people, is something that require partners to exercise a lot of patience, family issues are not situations for the police or judges that do worst things when they intervene."

There were negative responses when the availability of recognized services such as helping to promote education for prevention, surveillance, management, and general control in Yoruba communities, especially the study setting was mentioned. According to a 36-yearold secretary, "among the middle-aged adult women it is the social welfare office, and perhaps health care workers that should make the issue of family violence visible but there is nothing going on and we don't have a government that cares about anybody. You are on your own most of the time and if you are unfortunate as a woman to have married into a useless family, and have children for the man, too bad."

On a conclusive note, older men commented that some women also perpetuate abuse and violence against their husbands and children and that the researcher should not underestimate the implications of such. According to a 54-year-old man, "some women are also terrible and would use all forms of subtle abuse and direct violence with their husbands and children. Such women also push other men to resolve to have proper control of their wives. Besides, the modern woman needs to be a little careful with the modern approaches to controlling family violence. I think the Yoruba people have lost almost every good thing about human relationships that promoted group commitment by our modern ways of life."

\section{Discussion}

Family violence, from the enthusiasm shown by the participants in this study, appeared like an issue requiring active and urgent interventions among the Yoruba ethnic group. The use of qualitative method promoted gathering more information that would have been lost if data were gathered using closed-ended 
questions about known forms of abuse and violence in other cultures. For example, the dimension of the sexual touching ("tage") may not have come to limelight if one has limited the questions on sexual touch to questions on sexual harassment in the modern context. Sexual harassment in modern times to indigenous people may not be important to require formal action for change. The findings of this study showed a generational variation of responses from participants with older men accepting the practice of sexual touching, but totally unacceptable to the younger men probably because sexual touching may be toward younger women admirable to the younger men for stable relationships. While the older married men are just "touching" the younger women for the fun of it. The acceptability of some forms of abusive verbal exchange among this sub-ethnic group may also have been lost if quantitative method was used.

The definitions of family violence as all forms of violating behaviors, such as verbal and nonverbal, from this study were in congruence with some other definitions in the literature ${ }^{19-21}$ but with no single word that connote violence in the Yoruba context. The description of all the phrases indicative of violence is associated with power differences ${ }^{21}$ from age, marriage, gender, and family relationship in various aspects of economic, physical size, and authority that leads to hurt or harm of the victim. ${ }^{22,23}$

Understanding the view points of the Yoruba ethnic group about violence cannot be done in isolation but in relation to role assignment and obligation to perform assigned roles. Research ${ }^{24}$ has shown that none fulfillment of socially assigned roles by gender and in children upbringing as prescribed by the culture can be risk factors for violence perpetration and victimization on the part of the wife, husband, parents, and siblings. ${ }^{25}$ This is relevant because gathering data from specific ethnic groups with varying cultures in a place like Nigeria will bring explicit characteristics and beliefs of such ethnic group to the fore for specific intervention strategies that will be satisfactory and relevant to each group ${ }^{7,26}$ to enhance the effectiveness of such interventions. The finding is also important to community health nurses and social workers who must be able to assess family relationships for vulnerability to violence and intervene for violence control in context.

Distinguishing between violence and abuse was difficult among the participants from the findings of this study. Although it was expressed that violence may be intentional, there may be abuse without the abusers recognizing it, and without the victims recognizing the behavior as abusive. This may be argued that violence and abuse in the private spheres may not be intentional but ways to correct the victim and exercise control. This study affirmed that whichever concept used, violence or abuse, it is associated with harm to the victim and power differences within and across gender and age. ${ }^{27}$ So "harm" as the indicator of violating behavior whether intentional or unintentional needs to be propagated at all levels of mass mobilization, education, and interventions targeting all stakeholders.

Findings from this study also showed that perpetration of violence is not gender-specific and victims cut across gender and age categories. Although, some members of the family (children and women) are more vulnerable. Family violence can be perpetrated by females against females, males against males, and older siblings against younger siblings provided there is age or authority variance. Findings from this study also showed that economic power difference with a richer wife than the husband will increase her risk of family violence. This is in support of the findings of a Nigerian study $^{9}$ among married women.

Economic basis of power relation in the family is theoretically recognized and this also validates the discourse of gender-based violence. Nevertheless, there are cultural practices such as compulsory widowhood rites and wives as slaves which make women more vulnerable to abuse and violence than men in the Yoruba ethnic group harmonizing with practices in some other ethnic groups in Nigeria. ${ }^{28}$ Children and women were unanimously agreed by the participants of this study as family members who are affected more by violence and abuse while men are perpetrators supporting findings from previous studies. ${ }^{8,26,29}$ Also supported by the feminist theory that violence is mostly perpetrated by a male against a female victim. ${ }^{30}$ Women tolerating abuse and violence from the father in the house to prevent the children from suffering is a position by women who have far-reaching consequences for intergenerational tolerance and perpetuation of familial violence. ${ }^{31}$ Similarly supported by the social learning theory that behaviors, especially in family interactions, are learnt by children through observation, imitation, and reinforcement. ${ }^{32}$

Children as victims of family violence from the result of this study can be from parents, older siblings, or other members of the extended family in the form of punishment and incest. Incest is loathed among the Yoruba people but parents must be sensitized and educated on how to handle sexual violence. While, some behaviors referred to as violence or abuse of children in the developed countries may be seen as mode of upbringing and correction of children in the family milieu in the cultural context of the Yoruba people. Moderation in using this medium as corrective measures for children was mentioned but was not defined and specified. There is need for education and training of parents on alternate mode of child upbringing quite different to what they 
were exposed to growing up. Nurses are strategically placed to relate to families at different developmental levels, so they can promote positive parenting practices.

The management strategies from the findings of this study revealed that proper socialization with family values, similar to the emphasis placed on the need for education on harmonious family living, ${ }^{33}$ should be done in the light of differentiating good behaviors from bad as thought by the family, with the fear of the older citizens irrespective of the age difference. The older members of the family can correct the younger ones when they err. The older family members are also included in managing couples' disagreements of fights referred to as violence or abuse in this study. It was emphasized that no one should perpetrate violence but report any unacceptable behaviors to elderly family members who will invite the reported for correction and subsequent change. Some of the ways to imbibe proper values and advocate behavioral change of erring members were storytelling, sermons in religious houses, sharing experiences of old adults with younger members of the family and general discussions to discourage unpleasant behaviors among family members. Some of these strategies are not practiced in this modern time with the advent of social media platforms where group chat and family meetings are done electronically.

Mediation by family members, friends, and significant others was in use and was effective according to the findings of this study although there should be better ways of making perpetrators more responsible for their

\section{References}

1. Tolan P, Gorman-Smith D, Henry D. Family violence. Annu Rev Psychol. 2006;57:557-583.

2. Goh L. The Singapore strategy in managing family violence. Singapore Fam Physician. 2011; 37:8-16.

3. Department of Child Protection, Western Australia, Family and domestic Violence background Paper. 2012;2-10. https://humanrights.gov.au/sites/default/ files $/ 34.1 \% 20$ Family $\% 20$ and $\% 20$ Domestic $\% 20$ Violence\%20Background\%20Paper\%202012.pdf. Accessed March 5, 2019.

4. Nouhjah S, Latifi SM. Variation in the prevalence of domestic violence between neighboring areas. Int Sch Res Notices. 2014;2014.

5. Omidoyin TJ. Violence against persons (prohibition) act 2015: a positive step to the eradication of domestic violence in Nigeria. Nnamdi Azikiwe Univ J Int Law Jurispudence. 2018; 9:39-41. actions. Judicial intervention strategies through the police, social welfare officers, and health care workers are not evident within the community, hence the reliance on the informal ways of intervening with violence or abuse in the family.

\section{Conclusion}

Family violence at various levels of family relationships as driven by cultural beliefs. The control and management of abuse and violence are mostly done by family members, friends and significant others because the law enforcement agencies and modern judicial intervention strategies seem inappropriate among this ethnic group. This is probably due to the unacceptable win-lose outcomes associated with the formal approach and presumed male dominance by culture and in family relationships. Developing relevant interventions among this ethnic group requires working with family members to evolve culturally acceptable actions to make perpetrators responsible and sanctioned as to reduce the occurrence of family violence.

\section{Ethical approval}

Ethical issues are not involved in this article.

\section{Conflicts of interest}

All contributing authors declare no conflicts of interest.
6. Hawley FF. Subculture of violence theory. In: Miller JM, ed. The Encyclopedia of Theoretical Criminology. 1st ed. Blackwell UK; 2014: 851-855.

7. Nwabunike C, Tenkorang EY. Domestic and marital violence among three ethnic groups in Nigeria. $J$ Interpers Violence. 2015;32:18.

8. Bamiwuye SO, Odimegwu C. Spousal violence in sub-Saharan Africa: does household povertywealth matter? Reprod Health. 2014;11:1-10.

9. Onigbogi MO, Odeyemi KA, Onigbogi OO. Prevalence and factors associated with intimate partner violence among married women in an urban community in Lagos State. Afr J Reprod Heal March Afr J Reprod Heal. 2015;19:91.

10. Olotu OA. Child abuse among parents in Ekiti state: implication for guidance and counselling. Eur Sci J. 2013;9:260-269.

11. Olusegun OO, Idowu AA. Child abuse in Nigeria: dimension, reasons for its persistence and probable 
child abuse in Nigeria: dimension, reasons for its persistence and probable solutions. Child Fam Law J. 2016;4: Iss.1, Article 2.

12. Abdulkadir I, Umar L, Musa H, Musa S, Oyeniyi O, Ayoola-Williams O. Child sexual abuse: a review of cases seen at General Hospital Suleja, Niger State. Ann Niger Med. 2011;5:15.

13. Mudiare EPU. Abuse of the aged in Nigeria: elders also cry. Int J Contemp Res. 2013;3:79-87.

14. National Population Commission. Nigeria and ICF (2019) Nigeria Demographic and Health Survey 2018. Abuja, Nigeria, and Rockville, Maryland, USA: NPC and ICF. 2018.

15. Macro IC, National Population Commission. Nigeria demographic and health survey 2008. Abuja, Nigeria: National Population Commission and ICF Macro. 2009.

16. National Population Commission of Nigeria. Nigeria: 2013 Demographic and Health Survey; Key Findings. 2013;1-15.

17. Eckhardt CI, Murphy CM, Whitaker DJ, Sprunger J, Dykstra R, Woodard K. The effectiveness of intervention programs for perpetrators and victims of intimate partner violence. Partner Abuse. 2013;4:196-231.

18. Oloukoi J, Oyinloye RO, Yadjemi H. Geospatial analysis of urban sprawl in lle-lfe city, Nigeria. South Afr J Geomatics. 2014;3:128.

19. World Health Organization. Promoting gender equality to prevent violence against women. World Heal Organ. 2009;1-18. http://apps.who.int/iris/handle/10665/44098. Accessed March 5, 2019.

20. Zeleke H, Mengistu D, Alem G. Assessment of nurses preparedness and identify barriers to care women exposed to intimate partner violence in East Gojjam Zone, Ethiopia, 2014. J Nurs Care. 2015;4:2-10.

21. Ajibade GO. Yorùbà women in actions- violence in dialogue. Cah Etud Afr [Internet]. 2017;51:847871. [Available from: Domestic violence, Polygyny, Housewives, Women, Womens songs, African culture, Womanism, Husbands, Violence].

22. Condino V, Tanzilli A, Speranza AM, Lingiardi V. Therapeutic interventions in intimate partner violence: an overview. Res Psychother Psychopathol Process Outcome. 2016;19:79-88.

23. Kelly JB. Differentiation among types of intimate partner violence: research update and implications for interventions. Family court review. 2008;46:476-499.

24. Linos N, Slopen N, Subramanian SV, Berkman L, Kawachi I. Influence of community social norms on spousal violence: a population-based multilevel study of Nigerian women. Am J Public Health. 2013;103:148-155.

25. Cheung AKL, Choi SYP. Non-traditional wives with traditional husbands: gender ideology and husbandto-wife physical violence in Chinese society. Violence Against Women. 2016;22:1704-1724.

26. Arisi RO, Patrick O. Cultural violence and the Nigerian woman. Lwati A J Contemp Res. 2012; 9:69-79.

27. Kazaura MR, Ezekiel MJ, Chitama D. Magnitude and factors associated with intimate partner violence in mainland Tanzania. BMC Public Health. 2016;16:1-7.

28. Adika VO, Agada JJ, Bodise-Ere K, Ojokojo MEY. Men's attitude and knowledge towards gender based violence against women in Yenagoa, Bayelsa State. 2013;2:77-83.

29. Devaney J. Research review: the impact of domestic violence on children. Irish Probat J. 2015;12:79-94.

30. Mirza N. Family abuse in Scotland contesting universalisations and reconceptualising agency. 2015. https://www.era.lib.ed.ac.uk/bitstream/handle/ 1842/15938/Mirza2015. pdf? sequence $=1$. Accessed June 8, 2019.

31. Franklin CA, Kercher GA. The intergenerational transmission of intimate partner violence: differentiating correlates in a random community sample. J Fam Violence. 2012;27:187-199.

32. Rakovec-Felser Z. Domestic violence and abuse in intimate relationship from public health perspective. Heal Psychol Res. 2014;2:1821.

33. Pavithra S, Irudhaya Ananthi S. Analyses of domestic violence for women in Theni (DT). Int J Sci Res Comput Sci Eng Inf Technol. 2018;3:231-235. 